equatorial telescope, resulted in the discovery by the present writer of several additional objects of the same class. Still more recently, Dr. Copeland, during a journey to the Andes, has extended the list by the discovery of some similar stars in the southern heavens.

Among the photographic observations which have been undertaken at the Harvard College Observatory, as a memorial to the late Prof. Henry Draper, are included a series of photographs of the spectra of all moderately bright stars visible in the latitude of the Observatory. A recent photograph of the region in Cygnus, previously known to contain four spectra exhibiting bright lines, has served to bring to our knowledge four other spectra of the same kind. One of these is that of the comparatively bright star $\mathrm{P}$ Cygni, in which bright lines, apparently due to hydrogen, are distinctly visible. This phenomenon recalls the circumstances of the outburst of light in the star $\mathrm{T}$ Coronæ, especially when the former history of $\mathrm{P}$ Cygni is considered. According to Schonfeld, it first attracted attention, as an apparently new star, in 1600 , and fluctuated greatly during the seventeenth century, finally becoming a star of the fifth magnitude, and so continuing to the present time. It has recently been repeatedly observed at the Harvard College $\mathrm{Ob}$ servatory with the meridian photometer, and does not appear to be undergoing any variation at present.

Another of the stars shown by the photograph to have bright lines is D.M. $+37^{\circ} 382 \mathrm{I}$, where the lines are unmistakably evident, and can readily be seen by direct observation with the prism. The star has been overlooked, however, in several previous examinations of the region, which illustrates the value of photography in the detection of objects of this kind.

The other two stars first shown by the photograph to have spectra containing bright lines are relatively inconspicuous. The following list contains the desiunations according to the Durchmusterung, of all eight stars, the first four being those previously known:- $35^{\circ} 4001$, $35^{\circ} 4013,36^{\circ} 3956,36^{\circ} 3987,37^{\circ} 3821,38^{\circ} 4010,37^{\circ} 387$ I, $35^{\circ} 395^{2}$ or 3953 . Of these $37^{\circ} 3871$ is $\mathrm{P}$ Cygni, and $37^{\circ} 3821$, as above stated, is the star in the spectrum of which the bright lines are most distinct.

EDWARD C. PiCKERING

\section{PEAT FLOODS IN THE FALKLANDS}

$\mathrm{T}$

$\mathrm{E}$ accompanying narratives of a singular visitation which has befallen the town of Stanley in the Falklands may be of some interest to the readers of NATURE. Though the causes are so different, the effects of the bursting of a peat-bog in some respects curiously simulate those of a lava-flow. The papers have at different times been sent to Kew from the Colonial Office. It is partly in the hope that their publication may lead to some practical suggestion for dealing with the trouble that I ask for their insertion in your columns.

\section{W. T. THiseltoN Dyer}

The Acting-Governor Balley to Governor Callaghan, C.M.G.

Stanley, Falkland Islands, January I, I 879

SIR,-I regret to have to report to you the circumstances attending an accident which happened early on the morning of November 30 last.

Just after midnight on Friday, November 29, one of the inhabitants was awakened by the continued barking of his dog, and thinking that a cow had strayed into his garden, he went outside, when to his alarm he found that his house was surrounded by a black moving mass of peat several feet in height, and travelling down the hill at about four to five miles an hour. It was not until daylight that the extent of the disaster was manifested.

The sufferers by the calamity were quite shut off from communication with the rest of the settlement, until they had cut a way for themselves through the heap of liquid peat, which everywhere surrounded their dwellings. Fortunately no lives were lost.

Immediately, when the report reached me, I proceeded to the scene of the disaster, and found the town in a worse state than it had been represented, all communication between the east and west end of Stanley being entirely cut off, except by boats. At this time there was no perceptible movement in the mass of peat which covered the ground in confused heaps, except in Philomel Street and the drain on the east side-where I perceived the liquid peat moving down at a very slow rate. To get rid of this as quickly as possible, I found it advisable to turn all the water that could be damned up, and sluice the peat whilst in a liquid state, and by this means I eventually cleared Philomel Street. On following up the course which the slip had taken, the hill presented a curious appearance. From the peat bank, down to the brow of the hill, a distance of about 250 yards, the surface-peat lay in confused heaps direct from the opening of the bog. The moving power (whether water or liquid peat it is impossible to say) travelled over the ground faster than the heavier bodies, which were left standing 3 to 4 feet above the level of the ground.

Proceeding to the top of the bog, I found a depression extending over 9 to Io acres of ground, the edges cracking and filling up with water, and threatening another accident. I at once saw the necessity of calling upon the inhabitants to assist me in cutting a trench at the back of the hill, so as to draw off this accumulation of water, which scemed likely to float the loose peat left in the depression down into the settlement. I am glad to say that this call was heartily responded to by every man in the settlement, the gentlemen finding substitutes to take their places.

All worked for eight days in the cold and the rain, but nevertheless they were unsuccessful in carrying the trench through the bank into the bottom of the slip, owing to the soft peat welling up from the bottom and filling the trench again. Seeing that the exertions were of little avail in the present state of the bog, I did not press the settlers to continue the work that was so disheartening in its results; and as I now felt satisfied, from the great quantity of water that had been drained off, and the cutting being at a level, that this would prevent any further accumulation of water taking place in the slip, as there was no immediate danger of another accident taking place, the work was stopped, and I published the inclosed notice.

With your Excellency's permission I will, in the course of a few weeks, prepare sections of the bog and the settlement, showing a plan of drainage which will, I hope, prevent a similar accident happening again.--I have, \&c., (Signed) ARTHUR BAILEY

His Excellency Governor Callaghan, C.M.G.

\section{Lieut.-Governor Barkly to EARL Granville Government House, Stanley, Falkland Islands, June 3, I 886}

MY LORD,-I regret to have to report that a slip of the peat-bog at the back of the town of Stanley, similar to that which occurred in November 1878, but about 200 yards to the westward of the scene of that accident, took place last night. A stream of half-liquid peat, over ICO yards in width and 4 or 5 feet deep, flowed suddenly through the town into the harbour, blocking up the streets, wrecking one or two houses in its path, and surrounding others so as completely to imprison the inhabitants. Fortunately, as the night was wet and stormy, almost every one was within doors, and the few who were in the wrecked houses escaped in time. One child was, unfortunately, smothered in the peat, whose body has been recovered, but no other casualties are known to have occurred. An old man is, however, reported to be 
missing this morning, and it is feared he may also have perished, as part of his house is almost filled with peat.

(2) The people of Stanley, as on the former occasion, showed great energy and resource in dealing with the danger, and before I myself reached the spot barriers had been erected and lanterns placed to keep the public from dangerous spots, whilst all those who had been driven from their homes had been accommodated by their neighbours.

(3) This morning bodies of volunteers were early at work, clearing the streets, so far as it was safe to do so without risk of disturbing the superincumbent mass of peat and setting it in motion again, and draining the water from it as far as was practicable. I have also employed a strong body of labourers, under experienced supervision, in the same work, and have directed the removal of all persons remaining in dangerously situated houses ; and there is now little risk of further accident.

(4) The slip was caused, apparently, by the unusually heavy rains which have fallen during the last few days, and which the drains constructed by Mr. Bailey, the Surveyor, in 1878 , proved insufficient to carry off. Deeper and wider cuttings will now be made, and I trust that the recurrence of any similar catastrophe may thus be prevented. The town of Stanley is, however, from its situation and the mass of peat-bog on the high ground behind it, always to some extent exposed to danger of this nature in times of unusually heavy rainfall.-I have, \&c.,

$$
\text { (Signed) }
$$

The Right Hon. Earl Granville, K.G., \&c.

\section{THE BRITISH ASSOCIATION}

Birmingham, Tuesday

THE Birmingham meeting has been one of unusual excitement, mainly originating in the pre-arranged discussions which have taken place in several of the Sections. It is generally felt that this comparatively new feature bas given new life to the Association, and ought to become general in all the Sections. At present the arrangements are somewhat crude, and the discussions are apt to become unmanageable. In some cases each of the speakers has all he means to say already written out, so that the discussion becomes merely the reading of a series of papers on a given subject. In other cases, however, at the present meeting, the discussions have been to a large extent extemporaneous. This was especially so with the joint meeting of Sections A and D to consider the subject of colour-vision, and with the discussion in Section E on Geographical Education. Probably the most lively and generally interesting discussion was that which followed Mr. Seebohm's paper on Dr. Romanes' theory of Physiological Selection. Among those who took part in this were Profs. M. Foster, Newton, and Francis Darwin. On Saturday there was a lively and instructive discussion in Section C on Pre-Glacial Man, in which Prof. McKenny Hughes, Mr. Pengelley, Prof. Boyd Dawkins, Mr. De Rance, and others took part. The address of the President, Sir William Dawson, was a great popular success, so far as he could be heard. Prof. Rücker's lecture on soap-bubbles was universally admired, the experiments being unusually brilliant. Prof. Roberts-Austen's lecture to working men, on Saturday night, on the colour of metals, was greatly appreciated by a crowded audience.

The weather has not been so good as could have been wished, so that the excursions and garden parties have been somewhat damped. The soirée in the highly interesting Industrial Exhibition at Bingley Hall on Thursday evening was crowded and successful. Indeed the arrangements throughout made by the Local Committee for the entertainment of visitors have given complete satisfaction ; the comfort and convenience of the visitors having been provided for in every conceivable way.
At the meeting of the General Committee yesterday, it was resolved to accept the invitation to Bath for 1888 . For the Manchester meeting of next year, Sir Henry Roscoe was chosen President, the meeting to begin on Wednesday, August 3I. The fact of an invitation having been sent from New South Wales for 1888, has been already noticed in NATURE. The invitation came up for consideration yesterday, with the result that it was decided to send a deputation of forty or fifty representative members of the Association, to be selected by the Council in co-operation with the Sectional Committees. The New South Wales Government have offered to pay all the expenses of such a deputation, but they insist, in somewhat dictatorial terms, that the deputation shall consist only of the most eminent representatives of British science. This subsidiary meeting will take place in Sydney in January 1888 , when it is hoped representatives of science from all the Australasian colonies will assemble, and with the deputation hold a meeting, which will have for its object the promotion of science in Australia, and of more intimate relations between its representatives there and here. On the return of the deputation to this country it will report its proceedings to the Bath meeting; for the Australian meeting will not be regarded as a regular meeting of the British Association. On the whole, the decision come to at the General Committee meeting appears to give satisfaction. Victoria has also sent an invitation, but agreed to retire in favour of its sister colony.

The number attending the Birmingham meeting is about 2500 .

Dr. MacAlister read on Thursday last to Section A a communication from the Grenada Eclipse Expedition, announcing that excellent photographs had been taken of the eclipse, and that successful experiments with the spectroscope had been made in the northern part of the expedition by Dr. Schuster, Capt. Darwin, and Prof. Thorpe. Dr. Schuster obtained two good and two fair photographs of the corona. Good spectra of the solar prominences have been obtained, showing the bright lines of highly incandescent vapours. In this respect the result resembles that obtained in the two previous eclipses, though it was thought possible that this year, being one when sunspots are tending to a minimum, would be marked by the more continuous spectrum that bespeaks lower temperature. The bright lines were especially well marked when the slit of the spectroscope was tangential to the sun's disk, less marked when the slit was radial. Capt. Darwin was in charge of the coronagraph, an instrument by which a continuous series of photographs of the corona, before, during, and after totality, can be taken. Before and after the eclipse the photographs are taken by means of Dr. Huggins's device for mechanically shutting off the glare of the sun. The idea of Capt. Darwin's observations is to test the trustworthiness of Dr. Huggins's method. If a complete continuity appears in the series of pictures taken by what may be called the artificial and the natural methods, the confidence of solar observers in the former method will be established. The series has been duly obtained, but until the plates are closely scrutinised in England it is impossible to pronounce on the success of the test. Dr. Thorpe was in charge of an instrument prepared by Capt. Abney for the determination of the intensity of the light sent out from different parts of the corona. He has been very successful, having made no fewer than fifteen determinations.

The following is the list of grants which have been made this year by the Association :-

\begin{tabular}{lccccccr}
\multicolumn{7}{c}{ A-Mathematics and } & Physics \\
Solar Radiation & $\ldots$ & $\ldots$ & $\ldots$ & $\ldots$ & $\ldots$ & $\ldots$ & $£ 20$ \\
Electrolysis $\ldots$ & $\ldots$ & $\ldots$ & $\ldots$ & $\ldots$ & $\ldots$ & $\ldots$ & 50 \\
Ben Nevis Observatory & $\ldots$ & $\ldots$ & $\ldots$ & $\ldots$ & $\ldots$ & 75 \\
Standards of Light & $\ldots$ & $\ldots$ & $\ldots$ & $\ldots$ & $\ldots$ & $\ldots$ & IO \\
Instructions for Tidal Observations & & $\ldots$ & $\ldots$ & $\ldots$ & I5
\end{tabular}

